\title{
Intrasternomastoid spinal accessory nerve schwannoma: clinical and radiological correlation
}

\author{
A. Agrawal, K. S. Rao', J. H. Makannavar' ${ }^{2}$ L. Shetty ${ }^{3}$, V. M. Raveendra ${ }^{4}$ \\ Departments of Neurosurgery, ${ }^{1}$ Cranio-maxillofacial Surgery, ${ }^{2}$ Pathology, ${ }^{3}$ Radiology, ${ }^{4}$ Maxillofacial Surgery, Mangalore, India
}

\begin{abstract}
Accessory nerve schwannoma are extremely rare. The preoperative consideration of this diagnosis will lead to appropriate surgical management with preservation of motor nerve function. In this article we review the literature and report a case treated successfully based on preoperative MRI findings.
\end{abstract}

Key words: accessory nerve; intrasternomastoid; neck tumor; schwannoma; spinal root.

Accessory nerve schwannomas are extremely rare. To our knowledge there are only 19 reported cases in the literature. ${ }^{\mid 1-}$ ${ }^{5]}$ Only in two cases intrasternomastoid part was involved. ${ }^{[3,4]}$ The preoperative consideration of this lesion will lead to appropriate surgical management with preservation of motor nerve function. ${ }^{[3,4]}$

\section{Case report}

Thirty-seven-year-old lady presented with gradually increasing swelling in the upper part of neck on left side, not associated with pain or fever. On examination there was a $6 \times 7 \mathrm{~cm}$ size, firm, nontender, nonpulsatile, noncompressible, freely mobile swelling with smooth surface in left carotid triangle region. After contraction of sternomastoid muscle on the same side it was becoming more prominent and mobility was restricted in all directions more in side-to-side direction. There were no other swellings or lymphadenopathy. There were no focal neurological deficits. Her blood investigations were normal. Initial fine needle aspiration cytology (FNAC) of the lesion was suggestive of schwannoma. MRI of cervical region revealed a well-defined heterogeneously hypointense fusiform lesion on T1W becoming uniformly hyperintense on T2W images in the upper part of neck on left side with suggestion of funicular structure. The lesion was pushing the sternomastoid posteriorly and laterally and carotid sheath medially with its contents [Figure 1]. On exploration through a skin crease incision a firm yellowish mass with lobulated surface, with well-defined plane of cleavage was identified and dissected free from surrounding structures. It was originating from the left accessory nerve and pushing the sternomastoid muscle posteriory. Medially carotid sheath was identified and carefully preserved. The nerve was adhered to the tumor capsule proximally, and it was impossible to distinguish the bundle of the nerve fibers from the capsule distally. Tumor was excised totally and proximal part of the nerve was preserved. Postoperatively she developed mild weakness of left trapezius and sternomastoid muscle. Histopathological examination revealed a typical schwannoma, containing both Antoni types$\mathrm{A}$ and $\mathrm{B}$ areas.

\section{Discussion}

The majority of intracranial schwannomas arise from the acoustic nerve. Schwannoma arising from spinal accessory nerve are uncommon. Accessory nerve schwannomas may involve the cisternal, foraminal, and extracranial (spinal or intrasternomastoid) segments of the spinal accessory nerve. Schwannomas of extracranial segment of the spinal accessory nerve represent rarer form of tumor. ${ }^{[1]}$

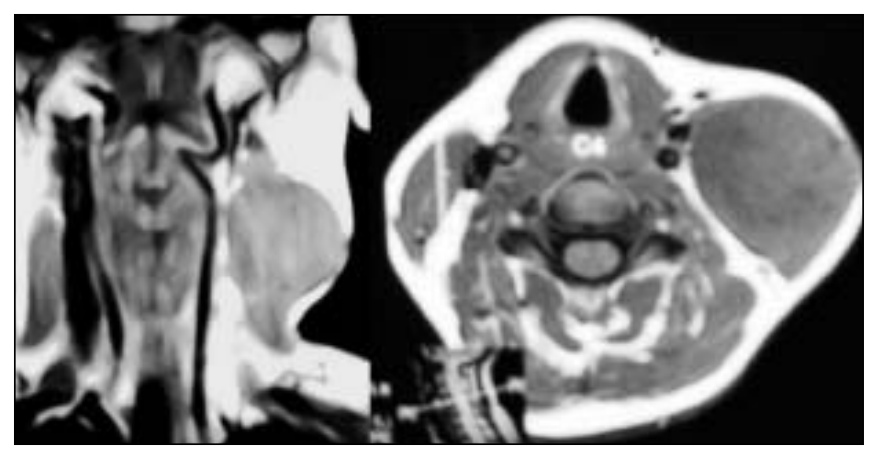

Figure 1: MRI T1-weighted coronal and axial image showing a heterogeneously hypointense mass below the skull base with clear periphery and a funicular structure (carotid sheath is pushed medially) 
Table 1: Summary of the 19 cases with accessory nerve schwannoma

\begin{tabular}{|c|c|c|}
\hline Author (year) & Origin of tumor & Location of tumor \\
\hline Gerhardt (1878) & Unknown & Jugular foramen \\
\hline Ruberti (1961) & Spinal root & Jugular foramen \\
\hline Pluchlno (1975) & Unknown & Jugular foramen \\
\hline Pou-Serradell (1978) & Spinal root & Jugular foramen \\
\hline Christoferson (1982) & Spinal root & Cisterna magna \\
\hline Tsuchiya (1982) & Cranial root & Cisterna magna \\
\hline Julow (1983) & Spinal root & Cisterna magna \\
\hline Julow (1983) & Spinal root & Cisterna magna \\
\hline Nishiura (1984) & Spinal root & $\begin{array}{l}\text { Cisterna magna to } \\
\text { spinal canal }\end{array}$ \\
\hline Matsushima (1985) & Cranial root & Cisterna magna \\
\hline McShane (1986) & Spinal root & Intrasternomastoid \\
\hline Kawaguchi (1987) & Spinal root & Spinal canal \\
\hline Nakashima (1988) & $\begin{array}{l}\text { Cranial root } \\
\text { spinal canal }\end{array}$ & Cisterna magna to \\
\hline Chang (1990) & Spinal root & $\begin{array}{l}\text { Spinal canal to } \\
\text { foramen magnum }\end{array}$ \\
\hline Iwasaki (1991) & Cranial root & Jugular foramen \\
\hline Sawada (1992) & Cranial root & Jugular foramen \\
\hline Noyek (1992) & Spinal root & Intrasternomastoid \\
\hline Kubota (1998) & Spinal root & Cisterna magna \\
\hline Tatebayashi (2003) & Spinal root & Cisterna magna \\
\hline Present case & Spinal root & Intrasternomastoid \\
\hline
\end{tabular}

Previously, 19 cases of accessory nerve schwannoma have been reported in the literature. ${ }^{[1-5]}$ [Table 1] shows a summary of origin and location of these cases. Twelve of the nineteen tumors were originated from the spinal root of the accessory nerve, five tumors originated from the cranial root and in two cases origin was not reported. Only in two cases intrasternomastoid portion of the nerve was involved. ${ }^{[3,4]}$ In our case also the location of tumor was intrasternomastoid with no deficits. On CT, these tumors are hypodense or isodense relative to surrounding parenchyma and hypodensity suggests areas of necrosis or cyst formation. ${ }^{[3]}$ MRI is superior to evaluate these lesions and these lesions are hypointense or isointense on T1-weighted sequences and hyperintense on T2-weighted sequences. With intravenous contrast there is moderate enhancement of solid components on both CT and MR and early scans may reveal slightly heterogeneous enhancement, whereas delayed scanning will show a more homogeneous pattern. ${ }^{[4]}$ Preoperative evaluation with imaging can correctly demonstrate the lesion. This will help in appropriate surgical approach and safe removal of tumor as in present case. ${ }^{[3,4]}$

\section{References}

1. Iwasaki K, Kondo A. Accessory nerve neurinoma manifesting with typical jugular foramen syndrome. Neurosurgery 1991;29:455-9

2. Kubota M, Ushikubo O, Mivata A, Yamaura A. Schwannoma of the spinal accessory nerve. J Clin Neurosci 1998;5:436-7

3. MeShane D, Noyek AM, Chapnik JS, Steinhardt MI, Cooter N. Schwannoma of the intrasternomastoid portion of the spinal accessory nerve:sophisticated preoperative CT diagnosis and appropriate surgical management. J Otolaryngol $1986 ; 15: 282-5$

4. Noyek AM, Chapnik JS, Wortzman G, Kandel R. Schwannoma of the intrasternomastoid portion of the spinal accessory nerve: sophisticated preoperative MRI diagnosis and appropriate surgical management. J Otolaryngol $1992 ; 21: 286-9$

5. Tatebayashi K, Tanaka Y, Numata H, Kawakami S, Kamitani H, Watanabe T. Schwannoma of the spinal accessory nerve in the cisterna magna. Surg Neurol $2003 ; 59: 217-22$.

Accepted on 24-06-05 